\title{
THE AMERICAN CHEMIST.
}

\author{
By Prof. G. C. Caldwell.*
}

I have chosen for the subject of my address as retiring president. of this society, one that seems appropriate to this occasion of the first gathering of a representation of American chemists on a fully organized basis as an American Chemical Society. My topic is the "American Chemist ; his Past and Present;" and if I were but a prophet I would venture to add, his future. Even as a historian I can claim neither special gifts nor training, and what I may have to say must be regarded only as a contribution to the treatment of so large a subject.

The earlier records of the work of the American chemist are to be found only in periodicals of a general scientific character; for it is only within comparatively recent years, as we know, that he has been fortunate enough to have journals devoted exclusively to his own science. Before the establishment of these chemical journals, the American Journal of Science and Arts, better known as Silliman's Journal, contained almost the entire record of his work. Besides and before this were only 'Transactions of scientific societies to which, however, he was but a meagre contributor, with a few notable exceptions.

The oldest of these Transactions were those of the American Philosophical Society of Philadelphia; contemporaneous therewith was the New York Medical Repository. My history begins with what $I$ can find in these periodicals or Transactions. Believing that the whole history can be presented in a more interesting manner if I divide the period over which it extends into distinct subperiods, I will give my account of it by decades after and inclusive

* An address delivered by the retiring President of the American Chemical Society at the sixth generu meeting, Pittsburg, Pa., December 28, 1892 . 
of the year 1800. What little there is on record of the American chemist's work prior to that year may be included in one period and set forth in a few words.

Of that time, just at the close of the last century, Dr. Priestley was the most prominent figure in chemical science. Indeed, if it had not been for his coming to this country, and his persistent devotion to the doctrine of phlogiston, and the opponents whom he aroused, there would have been exceedingly little to note of chemical work of any kind. As far back before this as 1 \%69 a paper was read before the American Philosophical Society, and published in the first volume of the Transactions, entitled "An analysis of the chalybeate waters of Bristol in Pennsylvania," by one Dr. DeNormandie. 'This being, I think, the first chemical analysis made in this country, an account of it in the author's words will not be inappropriate. It runs as follows: Exp. (I.) "A small portion of white vak bark infused in the waters ind uced an immediate change from transparency to a dark purple color, which it retained twentyfour hours without depositing any sediment. (II.) Some of the same water after being made hot, or exposed for a few hours to the open air, in a great measure lost its irony taste, and received no other color than that of a common tincture from the white oak bark. (III.) One drop of strong oil of vitriol in two ounces of the water produced no sensible alteration; and the water after standing some time continued transparent, without depositing any okerish or other sediment to the sides. (IV.) Ol. Tart. pr. deliq. dropped in some of the same water induced a change of color, rendering it somewhat yellow, and in time precipitated to the bottom of the cup a fine gold colored oker. (V.) Sixteen ounces avoirdupois carefully evaporated to dryness in a china bowl in B. M. [bain marie, $i$. e., sand bath] left one grain of a yellowish brown powder of the taste of tart. tartariz. (VI.) Linen moistened with the scum noating on the top of the spring is tinged with a strong iron mould. (VII.) This water in weight is exactly the same as rain water. From these experiments it is sufficiently evident that this water in its natural state contains a large portion of iron dissolved in pure water by means of an acid, which acid 18 extremely volatile and of the vitriolic kind." 
In another paper the author goes on to describe nine other experiments of the same sort, from which he concludes that his first deduction is confirmed that the water contains considerable iron, that the acid must be either vitriolic or nitrous, that there is a small portion of neutral salts in these waters, that they contain sulphur, and that they are slightly alkaline. The author then discusses the medical properties of the water, comparing it with the German Spa.

Nothing else appears till 1793 when there is published an account of an earthy substance found near Niagara Falls, and vulgarly called "spray of the falls."

We turn from such crude work as this, even though probably the best possible at the time and place, to that of Priestley, and his opponents, with a sense that we have hold of something of far greater importance, even if the main writer was all wrong in his theory. His first paper printed in this country appeared, I think, in 1796, in the same 'Transactions on " Experiments and observations relating to analysis of atmospheric air:" also further experiments relating to "Generation of air from water," the conclusion from which is that water is convertible into phlogisticated air. From this year on to the end of the century, he published numerous short articles in this periodical and in the New York Medical Repository.

In December, 1799, he read a paper before the American Philosophical Society on "Change of place in different forms of air through several interposing substances"' and, says Dr. Bolton, "recognizes distinctly for the first time the phenomenon of gaseous diffusion." In the volume of the New York Medical Repository for 1798-9, he published eight letters to Dr. Mitchell defending the doctrine of phlogiston. In the same journal Dr. J. Woodhouse, Professor of Chemistry in the University of Pennsylvania, had many papers, from $1 \% 95$ to 1800 and beyond, opposing Dr. Priestley's phlogistic views. What meagre showing this is, when we consider that, on the other side of the ocean, we find in the Annales de Chimie, the first volume of which appeared in 1789, such names of French chemists as Fourcroy, Lavoisier, Berthollet, Chaptal, Sennebier, Pelletier, Seguin, Vauquelin, Guyton 
de Morveau and others, as contributors, from 1789 to 1800, of articles on the greatest variety of chemical subjects; qualitative and quantitative analyses of minerals and mineral waters, studies of the chemical properties of elements and of their compounds, the chemistry of plant life and animal life, proximate analyses of some organic substances, the preparation of pure salts of various kinds, the illuminating power of different oils, besides the discussions on phlogiston, which were of course a prominent feature in the chemical literature of that period, when this theory was receiving its death blows at the hands of Lavoisier. Books on chemistry were published, such as Methode de Nomenclature Chimique, Traité de Chimie, Essai de Statique Chimique, System des Connaissances Chimique, Plitasophie Chimique; and in that same period the Annales de Chimie was started. In Germany there was Richter, author of Anfungsgrinden der Stöchiometrie, cler Messkunst Chemischer Elemente, and "Veber die neueren Gegenstande in der Chemie," in which he established by his own researches "the doctrine of proportions by weight, and showed that acids combined with bases to form salts, and developed the law of neutralization." There was also Klaproth, the first Professor' of Chemistry in the Cniversity of Berlin, who developed especially quantitative analysis, established by his improved methods the composition of many minerals, and discovered uranium, titanium and zirconium. In Sweden there was Scheele, who made a multitude of important contributions to chemistry, of which even a very imperfect enumeration would take too much of my time; and Bergmann, eminent as an analytical chemist and for his researches in analytical chemistry.

In England there was Cavendish who established the composition of water, and of nitric acid.

We pass on to the next decade, 1800-1809, when in England Sir Humphrey Davy first appeared prominently as a discoverer in chemistry, and published his account of the isolation of the metals potassium and sodium, and Dalton with his first developments of the atomic theory; when in Sweden there was the great Berzelius who, from $180 r$ on, devoted his entire energy to one great aim, the development of the atomic theory, and the first volume of 
whose Lehrbuch appeared in 1808; in France, Gay Lussac who, in 1808, announced the law of combination of gases by volume; Thenard, beginning in 1807 his investigations on the compound ethers; and Proust (really in Madrid, whither he went from France) who, in the last year of the preceding decade, began his fight with Berthollet, contending for eight years for the constancy of proportion in the composition of chemical compounds.

Surely something of the spirit of this great work going on in Europe should begin to make itself felt across the Atlantic, even though the communication between the new world and the old was still so difficult, and narrowiy limited. But there is practically nothing recorded in the only journals to which I have access, those already named, and there is good ground for believing that nothing important was done. Priestley was still contending for phlogiston with Dr. Morehouse and Dr. Mitchell, and performing some experiments of small account compared with what was being done abroad; such as "Observations on the discovery of nitre in common salt which had been previously mixed with snow," and "Transmission of acids, etc., in the form of vapor over several substances in hot tubes;" "Production of air by the freezing of water." Robert Hare, Jr., first appears in an "Account of fusion of strontites and volatilization of platinum," and B. Silliman in an "Analysis of a meteoric stone." Also, there is mention of perhaps the first soil analysis in America, under the title "On the substances which constitute the mineral soil of the environs of Boston."

All records fail me of any work done in the next decade, nothing being given in the above Transactions, till the appearance of Silliman's Journal in 1819 ; the eight short paper's of that year, one of them by Dr. Hare, and the others by Silliman, only one to four pages each, and relating to unimportant topics, merit no further mention.

In the twenties over seventy papers of chemical import were given in Silliman's Journal, of which sixteen, mostly by Robert Hare, and very short with but four or five exceptions, referred to new forms of chemical apparatus or to reagents ; seventeen, from one to seven pages in length, related to analyses of minerals; there 
were two papers on the present state of chemical science and three on atcmic weights, or points in chemical theory; other topics were generally of no special interest. In the Transactions of the American Philosophical Society, and in the Journal of the Franklin Institute which was started during this period, and the Proceedings of the Lyceum of Natural History of New York, were nine short papers, chiefly on analyses of minerals.

In the thirties about one hundred papers appeared in Silliman's Journal and the Journal of the Franklin Institute, nearly all of which were short-less than five pages long; but the character of the work, so far as indicated by the topics, was becoming higher; twenty-six papers related to studies of the properties of chemical elements or their inorganic compounds, and fifteen to studies in organic chemistry-none of them very deep perhaps, but still on a higher plane than heretofore; only fifteen related to analysis of minerals or mineral waters, six or eight to tęchnical matters, and seren to analytical methods; the remainder were on miscellaneous topics, mostly of subordinate importance. About twenty-five of the whole number of papers were contributed by Dr. Robert Hare, many of them very short, and, as in previous years, on new forms of apparatus or new methods of preparation of substances, in the devising of which he appears to have been very ingenious. No other single writer was so prominent in the records of either this or the preceding decades.

In the forties (1848) a new periodical was added, the Transactions of the American Association for the Advancement of Science. Furthermole, original work in chemistry took a wonderful start; and well it might; for such names appeared, familiar enough to some of the oldest of us, if not to the younger men in my audience, as W. B. and R. E. Rogers, the first of whom afterwards took an important part in the organization of the Massachusetts Institute of Technology ; J. Lawrence Smith, C. U. Shepard, John W. Draper, T'. Sterry Hunt, E. N. Horsford and W. Gibbs, many of whom had received their inspiration in the laboratories of Germany. Smith studied under Orfila, Dumas and Liebig; Draper, a native of England, under Dr. Turner of the University of London; Horsford under Liebig; Dr. Gibbs under Rammelsberg, Rose, Liebig and Regnault. 
Over a hundred papers appeared in the periodicals above named, and, while greater length does not necessarily mean much, nevertheless when papers of tell, fifteen, twenty pages or over, are the rule, rather than papers of two to four or five pages, it is not far out of the way to suppose that when such men as these I have named, and Silliman and Hare, write them, they are not made up of padding. Classifying these hundred or more papers roughly, about forty-three of them may properly be called purely scientific papers on inorganic chemistry, twenty on organic chemistry, twenty on analyses of minerals and waters, ten on analytical chemistry, and the rest on technical or other topics more removed from pure science. J. Lawrence Smith contributed eight of these papers; Hunt, ten; the Rogers brothers, eight. Dr. Hare was still prolific, contributing eight papers. Eight of the papers were purely theoretical; such as those on "The idea of an atom suggested by the phenomena of weight and temperature;" "Allotropism of chlorine as connected with the theory of substitution;" "Anomalies presented in the atomic volumes of phosphorous and nitrogen;" "Principles to be considered in chemical classification;" "Theory of compound salt radicals."

In the fifties about one hundred and seventy papers were published, against one hundred in the preceding decade, classified as follows: purely scientific, inorganic chemical work, about sixty; organic, eight; analytical, twenty-three; mineral analyses and studies, forty; technical subjects, nineteen; miscellaneous, eighteen. Several of these papers are theoretical studies; as, "Comparison between atomic weights and chemical and physical action of barium, strontium, calcium and magnesium, with some of their compounds;" "Numerical relations between the atomic weights, and some thoughts on the classification of the elements;" "Theoretical relation of water and hydrogen;" "Apparent perturbation of the law of definite proportions in compounds of zinc and of antimony;" "Rational constitution of certain organic compounds," etc. New and well-known names appearing prominently were those of Gentl, Mallet, Cooke (J.P.), Brush and C. M. Warren. Robert Hare's name disappears. Cooke in his article, above mentioned, on the numerical relations between the 
atomic weights, etc., classifies the elements in six series similar to the series of homologues in organic chemistry ; in each series the difference between the successive atomic weights is a multiple of some whole number, this number being different for the different series. He shows that the properties of the elements in each series follow a law of progression: the numerical law for the progression in the specific gravity is given; and when a sufhcient number of determinations shall have been made of such other properties as are capable of measurement, he predicts that numerjcal laws for each of these kinds of variation can be ascertained. Thus he looks forward to a perfect seience of chemistry in which we shall be able to foretell with certainty the properties, not only of undiscovered elements in any given series, but also of the compounds of these elements. There are many correspondences between his classification and that of Mendlejéef, and as above shown, he foreshadows the idea, already realized with the aid of Mendeljeef's classification, of the possibility of locating and deseribing hitherto unknown elements. Hunt contributed seventeen of the papers, largely given to the analysis and constitution of minerals; indeed the examination of American minerals was a very prominent feature of the chemical work of this decade, as shown by the number of papers on the subject. J. Lawrence Smith and Mallet did the largest part of their work on this line, and the former made an important contribution to the methods of analysis of minerals, in his new process for the separation of the alkalies. It was in this decade, that the famous work appeared of Gibbs and Genth on the Ammoniao-Cobalt Bases, covering 59 quarto pages of the Smithsonian Contributions to Knowledge-the longest single article that had up to that time appeared on a chemical research. A redetermination of the atomic weight of lithium and of antimony was made by Mallet, the first work of this kind done by an American chemist. It may well be said that this is the first decade of chemical research in this country which has some prominent and important characteristics to distinguish it from the others that preceded it.

In the siaties, about two hundred and fifteen papers were pub- 
lished, ugainst one hundred and seventy in the fifties, of which ninety pertained to general inorganic chemistry ; forty to organic chemistry, twenty-cight to methods of analysis and new forms of apparatus for analytical purposes; thirty to the analysis of minerals aud mineral waters; seven were on technical subjects ; fourteen on meteorites, four on agricultural chemical topics, and three on animal or vegetable physiological chemistry. More attention was given in this decade than in the preceding one to more purely scientific studies in general chemistry, for on inorganic and organic chemistry together there were one hundred and thirty papers, against only sixty-eight in the earlier period, while analyses of new minerals, also genuine scientific work, were almost as numerous as hefore. The most prominent contributor was Lea, nearly all of whose papers, over thirty in number, were on important topics in both inorganic and organic chemistry. Cooke and Horsford, of Harvard, and Gibbs and J. Lawrence Smith contributed important papers, as did also Hunt; Warren made some important contributions in organic chemistry. Other contributors were, Brush, Ordway, Crafts and Wetherill. Hinrichs first appeared with his theoretical essays, which some of us have perhaps attempted to master and assimilate. Of the papers on general inorganic and organic chemistry, about forty were from ten to thirty pages in length, indicating at least as to quantity of material to be communicated, research studies of considerable length. The proportion of such long papers was very much smaller in the preceding decades.

There is much work deserving special mention in this decade, such as Clark's "Constants of Nature," a collection of all the reliable determinations of specific gravities, boiling points, melting points, specific heats and expansion by heat, and covering 450 quarto pages of the Smithsonian Miscellaneous Collections; Warren's Monograph, of 100 quarto pages in The 'Transactions of the American Academy of Arts and Sciences, on "A new form of apparatus for fractional condensation of volatile liquids free from objections incident to the methods in use"; and "Researches on volatile hydrocarbons"; also, his papers on "A new method for combustion in a current of oxygen gas alone, 
withont the use of cupric oxide" ; and on "The analysis of organic substances containing sulphur and chlorine."

As one result of his work on the hydrocarbons, Warren showed that the elevation of the boiling point for an increment of $\mathrm{CH}_{2}$ in homologons series is $30^{\circ}$, or much larger than was hitherto supposed; and that in certain other series derived from the benzole series, differences in boiling points for $\mathrm{CH}_{2}$ added or removed are much smaller than $19^{\circ}$, Kopp's figure.

Worthy of mention is Lea's attempt at a classificition of the elements in several groups, the members of each group differing by 44-45, showing that "the elements thus grouped consist of bodies whose properties are analogous, - and that this classification is in harmony with the distinguishing characteristies of the substances classified." One such group starts with $\mathrm{Sb}, 120.3 ; \mathrm{As}, 75$; $\mathrm{P}, 31 ; \mathrm{N}, 14 ; \mathrm{Sn}, 59$ and $\mathrm{Pb}, 103.5$. Another comprises $\mathrm{Hg}, 200$; $\mathrm{Cd}, 112 ; \mathrm{Zn}, 65.5$ and $\mathrm{Mg}, 24.4$; all the members of this last group are in one of Mendeljéef's groups, and the first four members of the first group are also in another of Mendeljeef's. This grouping is founded on a broader basis; but Lea's was published thirty years ago, in 1860 .

Gibbs showed by reference to the volumetric relation of gaseous compounds that if the proposed new atomic weights, 16,12 and 32 be accepted for oxygen, carbon and sulphur, the atomic weights of least fifty other elements must be doubled; and as he is not a man to fail to give due credit to others, it is fair to infer that he was the first to call attention to this necessity. Lea's work on the ethyl bases as he calls them, diethylamine, triethylamine, etc., is comprised in several papers, in which he gives a very full account of their reactions, and a new method of separating them by picric acid. Ordway gave a very exhaustive paper on soluble glass, its chemistry and applications; Gibbs and Lea also made extensive researches on the platinum metils; and very notable are the many contributions made by Gibbs on improvements in methods of analysis; everything coming from his laboratory was reliable, and there was much of it. Hunt published three papers on the chemistry of mineral waters, in which, on the basis of certain general principles laid down, and of a number of analyses of waters 
of the Champlain and St. Lawrence basins, he attempted to trace the history of these waters and account'for their origin; and in another paper he attempted also to trace out the origin of the dolomites. Crafts, with Friedel, by jesults of research on the silicic ethers, proved as he thinks convincingly, the tetratomic character of silicium. Gaffield's interesting researches on the action of sunlight on glass were made in this decade. Gibbs made a very valuable contribution to the resources of physical chemistry, by a calculation of the wave lengths of the lines of a large number of the elements, from measurements made by Angström and Ditscheiner, and Huggin's scale of wave lengths of 1,000 lines. Goessman discussed in a careful and thorough manner the origin of the salt beds and the composition of the salt and the brine of the ocean water.

Three notable books appeared in this decade, Cooke"s Chemical Physics, Storer's Dictionary of Solubilities and Wormley's Microchemistry of Poisons.

In the seventies, about two hundred and forty papers were published, a part of them in three new periodicals. The American Institute of Mining Engineers issued its first volume of Transactions in 18i1. Methods of chemical analysis naturally occupied much of the attention of the chemical members of this Institute. 'The American Chemical Journal, and the Journal of the American Chemical Society made their first appearance in 18r9. This Society was established in $18 \% 7$, and published two volumes of Transactions, prior to the issue of the first volume of its Journal. Dr. Chandler's "American Chemist" also appeared in this decade.*

Eighty of the papers published referred to general inorganic chemistry; forty-seven to organic chemistry; fifty-seven to analytical methods and appiratus; only thirteen to minerals and mineral waters, and the same to technical subjects; twenty-one short papers were on meteorites; agricultural chemistry had fourteen papers, physiological chemistry fire, and sanitary chemistry two. Analytical chemistry was very much more prominent in the work of this decade, and in fact than at any time before it ; methods of agricultural chemical analysis, as well as of analysis pertaining to the mining engineering interests, especially of iron and steel, re-

*This Journal was begun in July; 1870, and completed seven vol imes, ending in 1876. It had been preceded by an American reprint of the Engtish Chemical News with an American Supplement. 
ceired special attention. The prominent contributors were M. C. Lea, J. Lawrence Smith, Gibbs, Remsen and Clarke; there were one hundred and thirty writers in all, of whom only fourteen contributed fire or more papers, and only two, Lea and J. Lawrence Smith, contributed over ten papers; but many of these papers were short. In mass and importance of material published Gibbs, Clarke, Mallet and Remsen ranked as high as the more frequent contributors, especially if they receive the credit due them for work done in their laboratories, although published in the names of their assistants or students. The beginning of Chittenden's extended work in physiological chemistry appeared in this decade. Remsen, C. L. Jackson and A. Michael also be. came prominent as leaders in research in organic chemistry. Gooch, besides giving us his crucible for filtration, published a valuable work on the determination of phosphorus pentoxide. Gibbs began his long and difficult research on complex inorganic acids, of tungsten and molybdenum. Clarke traced out some new relations between the atomic volumes of the elements. Hilgard began his work on the methods of analysis of soils, in which he is now the universally recognized authority. J. W. Draper showed that the diagram given in so many works at that time, and occasionally even now, exhibiting unequal distribution of heat and actinism in the solar spectrum are misleading-that on the contrary the heat and chemical power are as great at one end of the spectrum as at the other, the diffraction spectrum showing no such inequality as the diagram represents. Lea continued his research on the action of light on silver salts and also made new determinations of the atomic weights of nickel and cobalt. J. Lawrence Smith established the presence of a solid hydrocarbon and free sulphur in meteorites. Cooke made new determinations of the atomic weight of antimony.

While there are single researches in the preceding decade of higher importance than any that appear in this, a careful comparison of the whole amount of work done might show that there was little difference in the real advance made in the two decades.

In the eighties we see an enormous advance in chemical work. One new chemical periodical appeared, the Journal of Analytical Chemistry. 
Exclusive of papers on the examination of foods and drugs in the Reports of Boards of Health of three or four States, and of papers in Reports of Agricultural Experiment Stations, the whole number published was about ejght hundred and seventy-fire, and inclusive of papers excepted as above, the total would certainly not be less than nine hundred, or more than three and a half times as many as in the preceding decade. About one hundred and thirty of these papers related to general inorganic chemistry; two hundred and fifty-five to general organic chemistry; two hundred and eighty-three to analytical chemistry; over fifty to agricultural chemistry, twenty-five to technical chemistry; thirty to physiological chemistry; thirty-three to analyses of minerals and mineral waters, and also thirty-three, mostly very short papers, to analyses of meteorites. The amount of solid work on these several lines may be indicated in a measure by the length of the papers; a paper of one, two or even three pages, would as a general thing represent investigations of minor importance, and comparatively little actual work, although there may be some exceptions to the rule. Comparing in this respect the three leading lines of work, general inorganic chemistry, organic chemistry and analytical chemistry, about sixty per cent. of the papers in analytical chemistry are more than three pages long, while only twenty-two per cent. of the papers in inorganic chemistry, and nineteen per cent. of these in organic chemistry exceed that limit.

About three hundred and eighty chemists contributed these papers, of whom, however, two hundred and fifty-eight appeared but once or twice in the whole decade. The most frequent contributors were Clarke, Chittenden, Gibbs, H. B. Hill, Jackson, Morse, Michael, Mabery, Mallet, Remsen, E. F. Smith and Wiley; several valuable contributions were made by others, who published fewer papers, and in some cases very important ones.

The most notable feature in the work of this decade is the great amount of work in organic chemistry, done especially under the lead of Remsen, Jackson and Michael, most of which seemed to find its natural way to the public through Remsen's own journal. In these times when the Berichte, Liebig's Annalen, Journal für Praktische Chemie, Monatshafte and the Journal of the English 
Chemical Society are giving us every year their fifteen hundred pages and more of papers on research in organie chemistry, there are at least some of us who are not only not conversant with this work, our lines of study being in other directions. but are each year getting more and more hopelessly out of tonch with it. As one of those. I would not presume to pass judgment on the value of the researches in organic chemistry that are now being made in this comtry; bat we can be confilent that it is not such work as an American need be ashamel of; and I am sure we all rejoice that through these investigators our own country is contributing a large share of worthy research in this great branch of ical science.

In inorganic chemistry, Dr. Gibbs continued his work into this decade on the conplex organic acids. Morley contributed his masterly papers on the analysis of air and his work on the atomic weight of oxygen; Beckel, his digest of investigations on determinations of atomic weights since 1814, occupying 2i0 pages of the Smithsonian Miscellaneous Contributions to Knowledge: Clarke gare his recalculations of the atomic weights; M. C. Lan, his discovery of the allotropic forms of silver; Cooke and Richards, the redetermination of the atomic weights of oxygen and hydrogen; Mallet, his revision of the atomic weight of aluminum and determination of the molecular weight of hydrofiuoric acid; Craft's, his determination of the vapor density of iodine. with results differing from those of both Deville and Troost, and Victor Meyer, and his paper on the rapor density of permanent gases; and Warder, some of the first beginnings of work on physical chemistry.

I have had pointed out to me by a competent authority as the most significant papers in organic chemistry, "Oxidation of substitution products of the aromatic hydrocarbons," and "Iuvestigations on the sulphinides," by Remsen and his pupils; "Researches on the substituted benzyl compounds," by Jackson and his pupils; "Furfurol and its derivatives," by H. B. Hill, and "Researches on alloisomerism," by Michael and his pupils. Other leaders in this organte work were Mabery, L. M. Norton and W. A. Noyes. 
In analytical chemistry nothing more prominent appeared than Mallet's most valuable and exhaustive work, in the Report of the lamentably short lived U. S. Board of. Health, on "The determination of the organic matter in potable water" and Morley's on "The analysis of air." Analytical chemistry was much advanced along certain technical lines by the work of the Association of the Official Agricultural Chemists, begun in 1884, and by co-operative work on the analysis of iron and steel, published in the Transactions of the Institute of Mining Engineers.

In physiological chemistry, Chittenden continued with Ely and others the important work begun in the preceding decade, and published valuable papers on the digestive liquids and the products of their action on the proteids. In sanitary chemistry the work begun by the lamented Nichols in the seventies was carried further in this decade by Mallet in the paper on the determination of organic matter in potable water, already referred to, and the valuable papers by Leeds on potable water supplies, in Reports of the N. J. State Board of Health and the Journal of this Society. A large amount of work on the examination of foods ind drugs was done under the supervision of the Boards of Health of a very few States, notably Massachusetts and Ner York, and of certain cities.

In agricultural chemistry, under the generous provision made by the U. S. Government by an Act passed in 1886, giving $\$ 15,000$ annually to every State in which an Agricultural College wits established under the Act of 1862, and the no less generous provision made by some of the States themselves, a very large amount of work has been done. So close are the relations of chemistry to agriculture, that the opening and liberal equipment of a chemical laboratory for special work was among the first steps taken, on the establishment. of each agricultural experiment station under this grant; thus at present a chemist, with often one or more assistants, is exclusively engaged in each State in agricultural chemical investigation. Under the liberal appropriation made also by the Dspartment of Agriculture for chemical iuvestigation, more liberal than by any other Government, a large amount of valuable work has been done at Washington. In the outcome 
of these various provisions may be included Atwater's papers on the sources of the nitrogenous food of the plant, Richardson's on the composition of American cereal grains, the work of Jordan, Armsby and their associates on the digestibility and feeding value of fodder materials, and Hilgard's continuation of his work on soil analysis. Many papers were published on improvements in methods of agricultural chemical analysis, and a very large amount of routine work was done in the examination of commercial fertilizers for the purpose of protecting the consumers from fraud. In all this a prominent part was taken also in this decade by Johnson, Goessman, Jenkins, Babcock, Osborne and others.

'Thus my history closes: a hurried one, and therefore imperfect, but nevertheless giving, I trust, something of an idea of what we have come to in this country, from very small beginnings. From about eighty papers in the twenties, the first decade in which any work of importance was done, to over nine hundred in the eighties is great progress: and the progress justly appears greater, when the character of the work is also taken ints account. In the twenties the papers were mostly about the analysis of minerals, or new forms of apparatus or new reagents-and mostly very short papersand in general much below the grade of work that was going on in Europe: in the eighties the work was on the same lines and of the same order as that done elsewhere, and, as well as that, rich in important results.

But there is room for further progress still, much of it, before we in this country shall accomplish as much as our brother chemists do in Europe; before our Chemical Society shall, if it publishes a journal, be able to send ont annually such a volume as the Berlin Society does, to say nothing of what appears in other German periodicals.

What are our prospects, and what our means for doing this? This kind of work is done at the universities of Germany and her technical schools. We have universities; more of them, so-called, than Germany has; we have a few technical schools of a high order, and innumerable colleges. These universities and technical schools have their chemical laboratories, as have also many of the colleges. Every State has its agricultural experiment station, 
with a working chemical laboratory. So far then, as concerns laboratories, and men in charge of them more or less specially educated as chemists, there is abundant provision. Every one of these universities, colleges and advanced technical schools has a double mission to perform, if it does the whole work that is expected elsewhere in the world, of institutions giving higher instruction. One of these missions is to teach-to impart knowledge that is already a part of the world's possession of knowledge, to the students who are seeking it, now in larger numbers than ever before. 'The other mission is to gain new knowledge-to add to the world's stock of it. Here and there is seen a man of wealth, and scientific tastes and acquirements, and an aptitude for research, who investigates in his own private laboratory, and does good work there; but such a combination is rare. These higher institutions of learning are to be in the future, as they have been in the past, the fittest places, and indeed almost the only places, for the making of both investigators and investigations.

Why is it, with so many of these institutions as we have, making claim to this high rank in our system of instruction, that we fall so far short of contributing our full share of the world's acquisition of new knowledge, year by year? The first and perhaps most important reason is that those upon whom this work devolves, and who would be glad to do it, have no time for it. Their work of instruction, often comprising many branches of science, uses up all their energy. This unfortunate condition of affairs is chargeable, to a large extent, to the multiplicity of colleges with endowments inadequate for the performance of the whole work of a college. It may be fairly said that no institution of learning is fully worthy of being called a university, or a college of high rank, that does not provide teacher's enough, so that each one has spare time for investigation. There is room for improvement in this respect, even in some of our largest universities. It is not always practicable for an outsider, such as the average trustee is, to get so thorough an acquaintance with the inner workings of the several departments, as to understand how most of a teacher's time may be consumed in the management of the petty details of a laboratory full of students, prorided that he does his duty there. 
Secondly, given the time when this important feature of college and university comes to be properly appreciated, will there be means for the work. There can be little doubt that they will then be provided; if not in any other way, when it appears that thers are men ready and competent to carry on valuable investigations, but who cannot for want of means and appliances, new funds for the promotion of such work may perhaps be added to those already in existence-such funds as the Elizabeth Thompson Science Fund, now amounting to $\$ 26,000$, the Buche Research Fund, and the Wolcott Gibbs Fund for chemical research.

Given time and means, have we the men in this country for creditable scientific research? I think that such an answer to this question as is indicated by the records of the chemical research in the decade from 1880 to 1890 is most encouraging. Great investigators like great poets, like men great in anything, are born not made; born, may we not truly say, out of the, spirit of the country and the period in which their great works are done. But, when born they must be nurtured, and the place for their nurture is the university. In this sense the university must make the investigator as well as the investigation. In the land where the spirit of investigation is rife there will be the most material out of which to make investigators; and there too will men and women destined to be such be most sure to drift in to the line of life work for which they are best adapted and receive the best trainmg for it.

It seems to me that the relations of our Society to this matter of the furtherance of chemical investigation in this country are of vital importance; that if it does not appear in its stated meetings or the meetings of its sections scattered throughout the country, that it is alive with the spirit of research, it will fail to establish its reason for being; that membership of it will be of little advantage to anybody, and that the Society itself will be of little service to the country.

If I may be allc wed a personal allusion I would say that it seems to me that in assuming membership of this Society $I$ have also assumed a new duty: a duty to put forth special effort for the accomplishment of my share towards placing it on a par with other similar societies in its contributions to new scientific and technical 
knowledge. If a spirit somewhat akin to this prevails amongst its members, both old and new, then shall we fully and honorably establish its reason for being.

It seems to me, further, that the eridence thereof will be looked for in the Journal of the Society; as we see in the Berichte the magnificent evidence for the reason for the existence of the Berlin Society; or, in the Journal of the English Chemical Society the evidence for the reason for the existence of that Society

If most or even many of us feel no sense of a duty incumbent upon us to do earnestly whatever is in our power to advance the interests of this Society in the direction that I have indicated, and also to put into its journal a fair share of our testimony to this earnest endeavor, then I believe that our Society will lead a comparatively worthless life. It is my sincere hope that we may escape such a lamentable failure of our new efforts to establish an American Chemical Society worthy of its name. 